schen dem Ober- und dem Unterkasten mit der Drahtebene zusammenfällt. Diese Gußform wird mit Woodschem Metall ausgegossen. Aus dem Gußkörper können

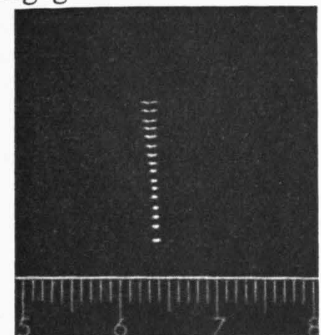

Abb. 2. Fokalbilder in der Umgebung des Brennpunktes einer praktisch ausgeführten Fokussierungseinheit. die Drähte entfernt werden, wodurch eine Vielzahl von Kanälen mit den gewünschten Eigenschaften verbleibt, Als Drahtmaterial hat sich Cekas bis zu einem Durchmesser von $50 \mu$ gut bewährt.

Aus der Abb. 2 kann die natürliche Größe des Brennfleckes einer praktisch ausgeführten Fokussierungseinheit mit 20 Kapillaren $(L=50 \mathrm{~mm}, d=0,1 \mathrm{~mm})$ und einer Fokaldistanz $f$ von $73 \mathrm{~mm}$ entnommen werden. Der Brennfleckdurchmesser von 0,4 mm stimmt mit dem errechneten Wert völlig überein. Für die Aufnahme wurde der Abstand zwischen dem Film und der Fokussierungseinheit zwischen 50 und $80 \mathrm{~mm}$ in Intervallen von jeweils $2 \mathrm{~mm}$ variiert. Diese Fokussierungseinheit wurde für Untersuchungen mit einer $57,3 \mathrm{~mm}$-SeEmanNBoHurs-Kammer angefertigt.

\section{Direkte Aufzeichnung von Spektren}

Von W. Lugscheider

Institut für Angewandte Physik der Technischen Hochschule Wien (Vorstand: Prof. Dr. F. LiHL)

(Z. Naturforschg. 18 a, 1372 [1963] ; eingegangen am 22. November 1963)

Die direkte Aufzeichnung von Spektren erfordert eine hohe Empfindlichkeit des Abtastelementes zur Erzielung eines befriedigenden Auflösungsvermögens. Dies führt zu der bekannten Anwendung des Photomultipliers. Es kann jedoch durch die Verwendung eines hochempfindlichen Photoleiters eine einfachere Meßmethode angegeben werden.

Ein photoleitender CdS-Kristall befindet sich knapp hinter einem verstellbaren Spalt, auf den die Linien scharf abgebildet werden. Der Widerstand des Halbleiters ist abhängig von der Intensität und der Wellenlänge der Linien. Ist die Abhängigkeit der Widerstandsänderung von der Wellenlänge bekannt, was bei dem verwendeten Photoleiter der Fall war, so können die Intensitäten der Linien quantitativ verglichen werden.

Aus der Änderung des Photowiderstandes wird eine Spannung abgeleitet, die entweder oszillographiert und photographisch festgehalten oder von einem entsprechend empfindlichen Schreibgerät aufgezeichnet werden kann.

Als Anwendungsbeispiel wird in Abb. 1 oben die Auflösung der e-, f-, g-Linien des $\mathrm{Hg}$-Spektrums gezeigt. Zum Vergleich zeigt Abb. 1 unten eine photographische Aufnahme des gesamten Spektrums.

Die maximale Genauigkeit wird durch die Aufzeichentoleranz des Oszillographen vorgegeben. Im gezeigten Beispiel beträgt sie $\pm 2,5 \%$.
Die in Abb. 1 a oszillographierte Meßspannung wurde auch einem Kompensationsschreibgerät zugeführt. In dieser Anordnung kann durch das Wegfallen jeglicher Filmmanipulation sehr rasch ein quantitativer Überblick erzielt werden. Wegen der Trägheit des Halbleiters soll die Abtastgeschwindigkeit nicht mehr als 0,2 $\mathrm{cm} / \mathrm{sec}$ betragen.

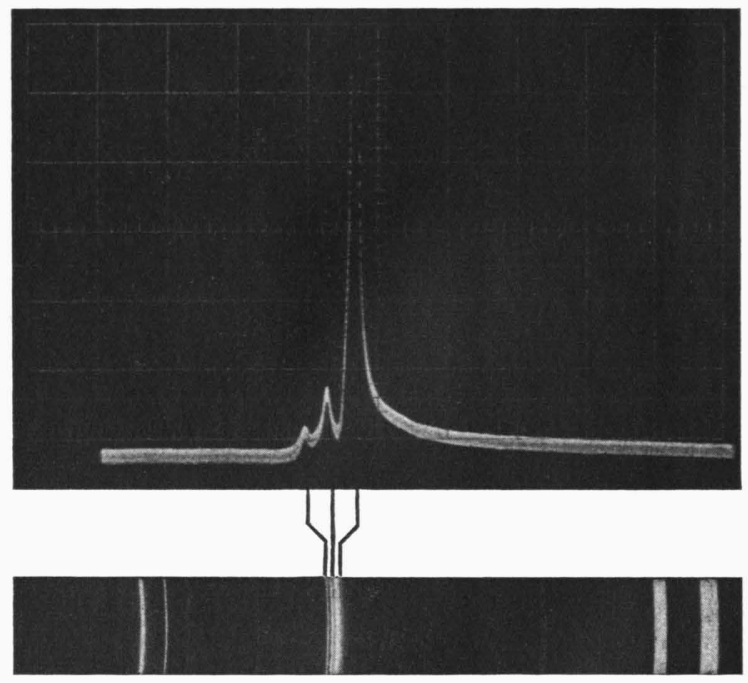

Abb. 1. Oben: Auflösung der e-, f-, g-Linien des Hg-Spektrums. Unten: Photographische Aufnahme des gesamten Spektrums. Empfindlichkeit : $2 \mathrm{mV} / \mathrm{cm}$; Horizontalablenkung: $2 \mathrm{~cm} / \mathrm{sec}$; $1 \mathrm{~cm}$ der Abszisse entspricht $25 \AA^{1}$. Die Breite des Abtastspaltes betrug $0,05 \mathrm{~mm}$.

${ }^{1}$ H. Kayser u. R. Ritschl, Tabelle d. Hauptlinien d. Linienspektren aller Elemente, Springer-Verlag, Berlin 1939. 